THE NEW EIFFEL PHOTOGRAPHIC IELIOGRAPH.

$$
\text { PHOTOGRAPHIC }
$$

Bouguer, in order to measure the luminosity of the sun's disk, allowed a beam of sunlight to enter a dark room through a small aperture, behind which a converging lens was placed. The diverging cone of rays, beyond the focus of the lens, was intercepted by a screen, forming a circle, the brightness of which was not too great to be measured by the ordinary methods. The brightness of the sun was assumed to bear the same ratio to that of the circle on the screen that the area of the circle bore to that of the aperture through which the light entered. At a later date (1844) Fizeau and Foucault employed the photographic process which had just been discovered by Daguerre to compar the brightness of the sun with that of artificia sources of light. The quantity of light received by a unit of area of the solar image formed at the focus of a telescope is proportional to the clear aperture of the object glass. Fizeau and Foucault received the image of the sun on an iodized plate of silver. In successive experiments they varied the aperture of the objective and regulated the duration of the exposure so that the final tint assumed by the plate and, therefore, the quantity of silver iodide decomposed, was the same in each case. In this way they proved that the required length of exposure, within certain limits, varied inversely in proportion to the aperture of the objective. In other words, the total chemical effect was found to be (within the range of exposure) proportional to the total quantity of light received by the image during image during the exposure. Then, by sun with that of a circular area, of the same apparent diameter, of the positive carbon of an electric lamp, they proved that the chemical effect is proportional to the brightness of the source of light. This relation, however, did not of reduced, whic was at first proportional to the length of the exposure, tended toward a fixed limi when the exposure was greatly prolonged. In 1881 the great advance which had been made in photography enabled Janssen to employ very sensitive plates, in which the total chemical effect remained proportional to the duration of exposure within very wide limits. Jordan devised a heliograph in the form of a perforated cylindrical box containing a sheet of ferroprussiate paper, and Richard constructed another instrument based on the photographic action of the solar rays.

Campbell, on the other hand, made use of the heating effect of the solar rays for the purpose of measuring the effective annual duration of sunlight, i. e., the aggregate time during which the sun is not veiled by clouds, a quantity which plays an important part in the processes of vegetation. Campbell's heliograph consists of a sphere of glass, mounted on a horizontal base, in a place exposed on every side, so that the sun is visible from its rising until its setting. A groove in the spherical mounting allows the intro-

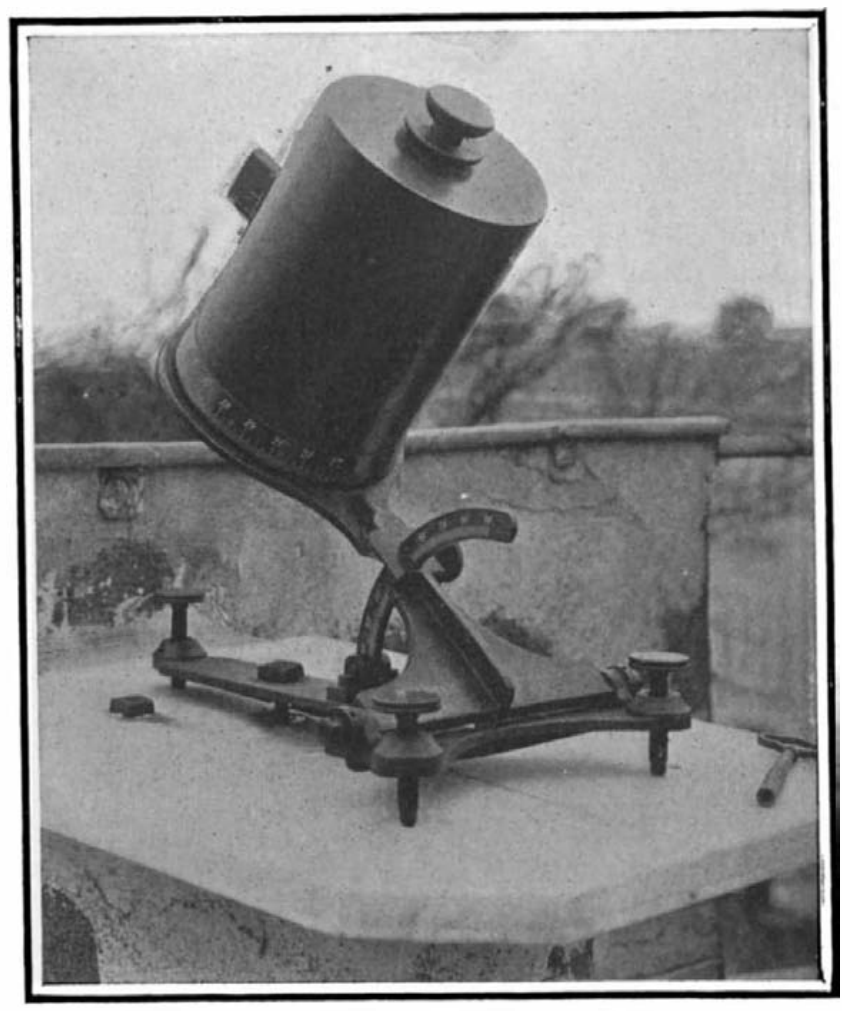

THE EIFFEL PHOTOGRAPHIC HELIOGRAPH.

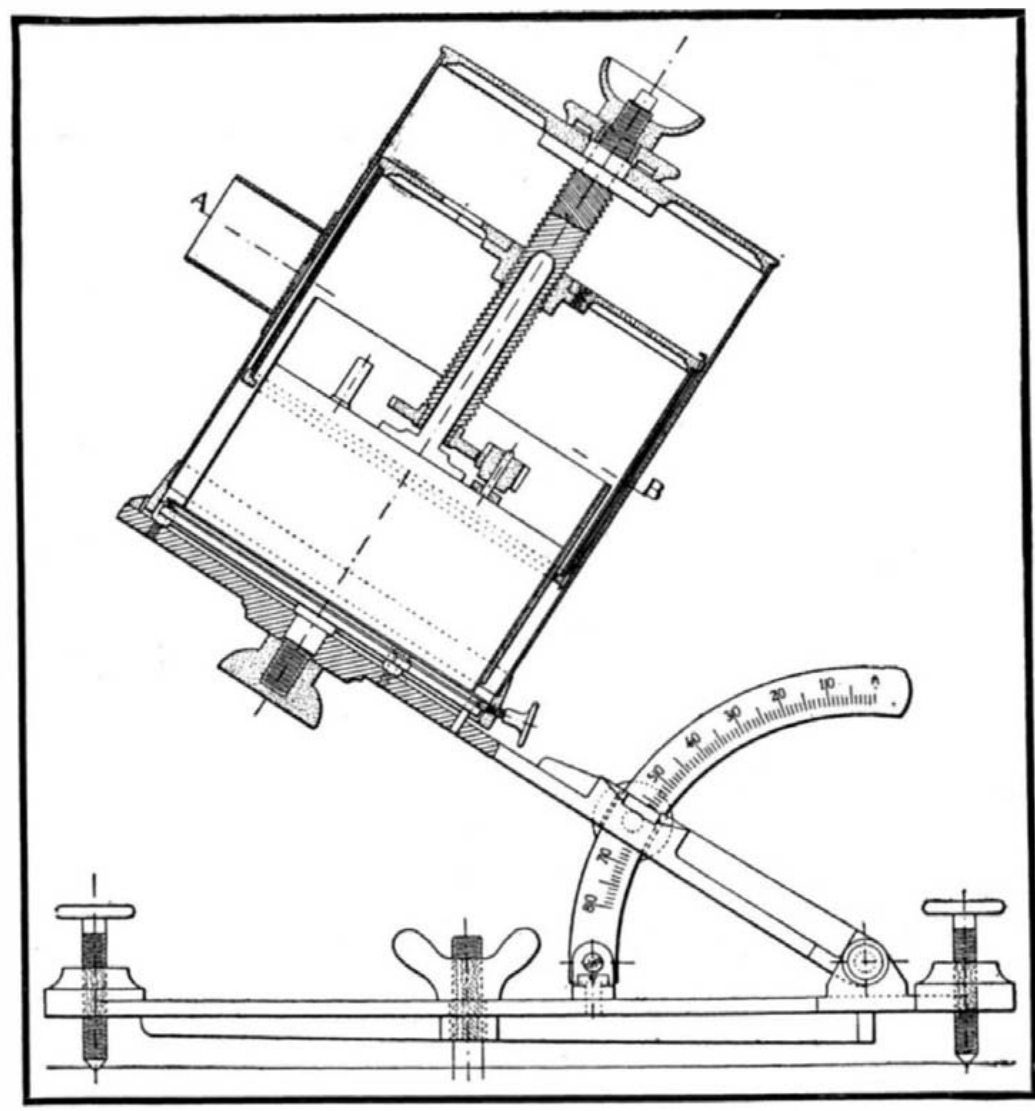

VERTICAL SECTION OF THE EIFFEL HELIOGRAPH.

uction of a strip of cardboard, which forms a circular arc at such a distance from the spherical glass lens that the image of the sun, formed by the always on the strip. The cardboard is carbonized by the concentrated solar rays at the spot where the image is formed and, owing to apparent diurnal motion of the sun, a black line is traced on the card. If the sun shines all day without intermission this line is continuous, but if the solar rays are intercepted by fleeting clouds the trace consists of a number of separate portions, the positions and lengths of which show when and how long the sun has shone. The apparatus is easily set up. It is necessary only to level the base, to place the noon line, marked XII on the card, oppcsite a fixed mark on the frame, and to set the in. strument so that the sun's image falls exactly on this line at the instant of true noon. In the improved form of the instrument designed by Stokes, the frame has three grooves, at different heights, in which three sorts of cards are placed. The shortest cards are placed in the highest groove and are used between November 5th and February 5th, the longest cards are placed in the lowest groove and are used bétween May 5th and August 5th, while the cards of intermediate length are placed in the middle groove and are used during the remainder of the year.

Eiffel has recently invented a photographic recording heliograph which has been used for some time at the central meteorological bureau of France and at the Juvisy observatory. It consists of a cylinder, which is mounted on a shaft parallel to the earth's axis, and is turned by clockwork at the rate of one revolution in twenty-four hours. The sun's rays enter the cylinder through an aperature in its convex surface, which is surrounded by a hood for the exclusion of diffused light. An inner cylinder, covered with photographic paper, is supported by a nut which can move along the shaft of the outer cylinder, which shaft bears a screw-thread. A guide, attached to the case of the clockwork, prevents the inner cylinder from rotating. Hence, as the outer cylinder turns, the inner cylinder is compelled, by the screw, nut and guide to move along the shaft, without rotating. The photographic paper is surrounded by a screen, which has various degrees of transparency in its various parts, corresponding to the average intensity of sunlight at different hours and seasons. As the outer cylinder rotates, its aperture is always directed approximately toward the sun and, in consequence of the motions of the two cylinders, the entering pencil of light traces a helicordal line on the paper, which is wide enough to serve for a number of days. No new conclusions can be drawn trom the photographic records made by the Eiffel heliograph until after the instrument has been in continuous operation for several years.

CARDIN PROCESS OF PHOTO-SCOLPTORE.

The idea of employing photography as an aid to sculpture soon followed the invention of the daguerreotype. Fifty years ago, Willème devised a process in which the sculptor's mode was photographed simultaneously by twenty-four

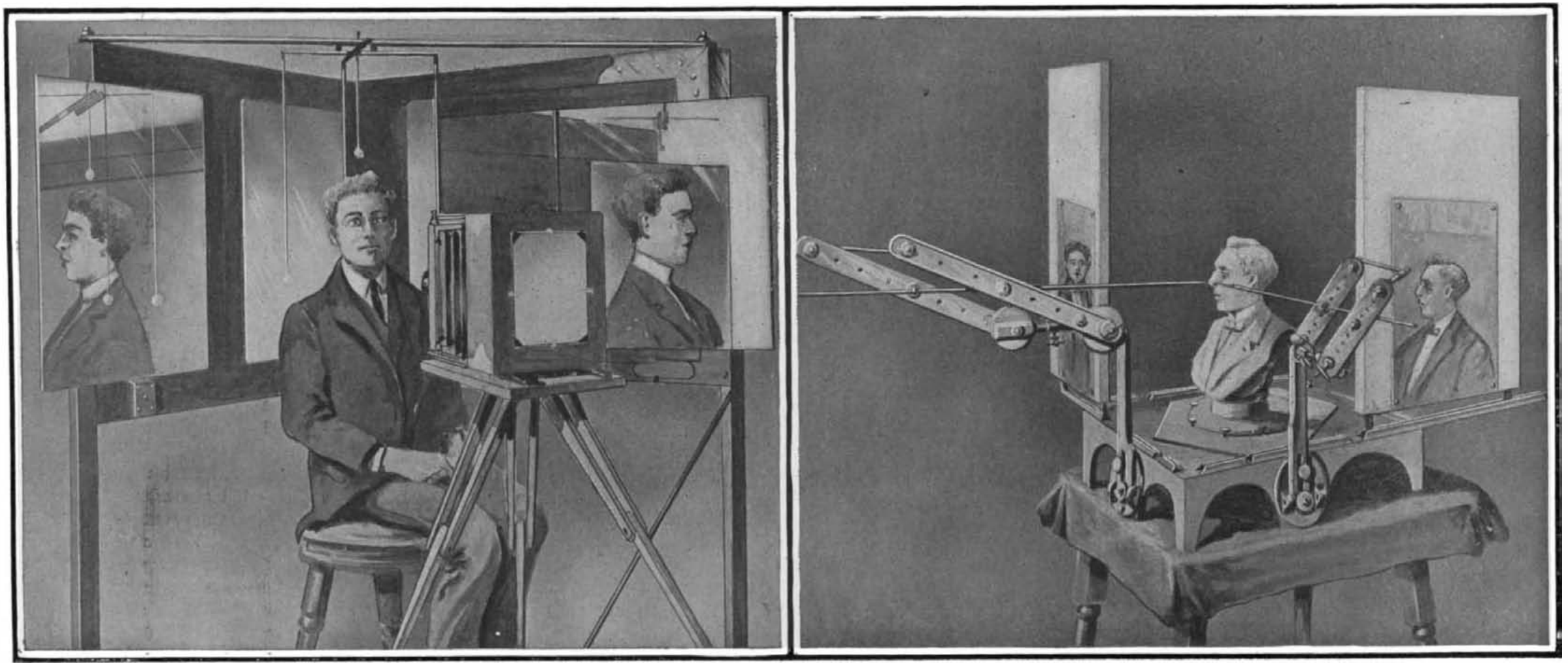

Fig. 8.-Cardin's apparatus for photographing the sitter from the front, back, and both sides simultaneously with a single camera.

Fig. 1.-Cardin's apparatus for modeling from four photogruphse 
cameras, arranged in a semicircle. A paper positive is made from each of the negatives and the twenty. four prints are cut out along the outline of the figure, and are then cut in two vertically. The forty-eight profiles thus obtained are assembled radially about a vertical axis in their proper relative positions. By filling in the intervals with a plastic mass a fairly complete sketch of the figure is obtained.

This process may be varied as follows: A mass of clay or modeling wax is placed on a revolving circular platform, the circumference of which is divided into twenty-four equal parts. The approximate form of the model having been given to the mass, by the usual methods, the outline of the figure in one of the (entire) photographs is followed with the tracing point of a pantograph, which is so constructed and arranged that its copying point plows a furrow in the mass of clay. The platform is then turned through one division, and a second furrow is made from the second photograph. This process is repeated with each of the twenty-four photographs, and the clay between the furrows is carefully removed. A very skillful hand is required to perform this operation so as to reproduce every detail of the model, but the object of this and all other processes of photo-sculpture is to produce, not a finished statue or bust, but a sketch as nearly accurate as possible.

The new Cardin process possesses the advantage of requiring only one photographic camera. Fig. 2 illustrates the method of making the photographs required for a portrait bust. The sitter is posed, facing the camera, before a triple mirror, by means of which the back and sides of the head are photographed by reflection. As the sitter's face and the three virtual images formed by the mirrors are unequally distant from the lens, the four im ages formed by the latter are not in sharp focus in the same plane. For this reason the ground glas focusing screen is made in four sections, and the plate holder is contrived to hold four plates, side by side, but in slightly different planes. The same cause produces differences in the scales of the fou photographs, but in making th enlarged copies which are employed in the operation of modeling, these differences are easily removed with the aid of the plummets which are suspended above and at each side of the sitter's head, and which appear in each photograph and indicate its scale.

The modeling apparatus is shown in Fig. 1. A vertical post rises from the center of the square iron platform $S$. Two photographs, a front view $T$ and a profile $E$, are supported in a vertical position by frames which slide in guides bordering two adjacent sides of the table. These sides are furnished with jointed supports, which carry long rods, $A$ and $B$. The rods can slide lengthwise in their supports and

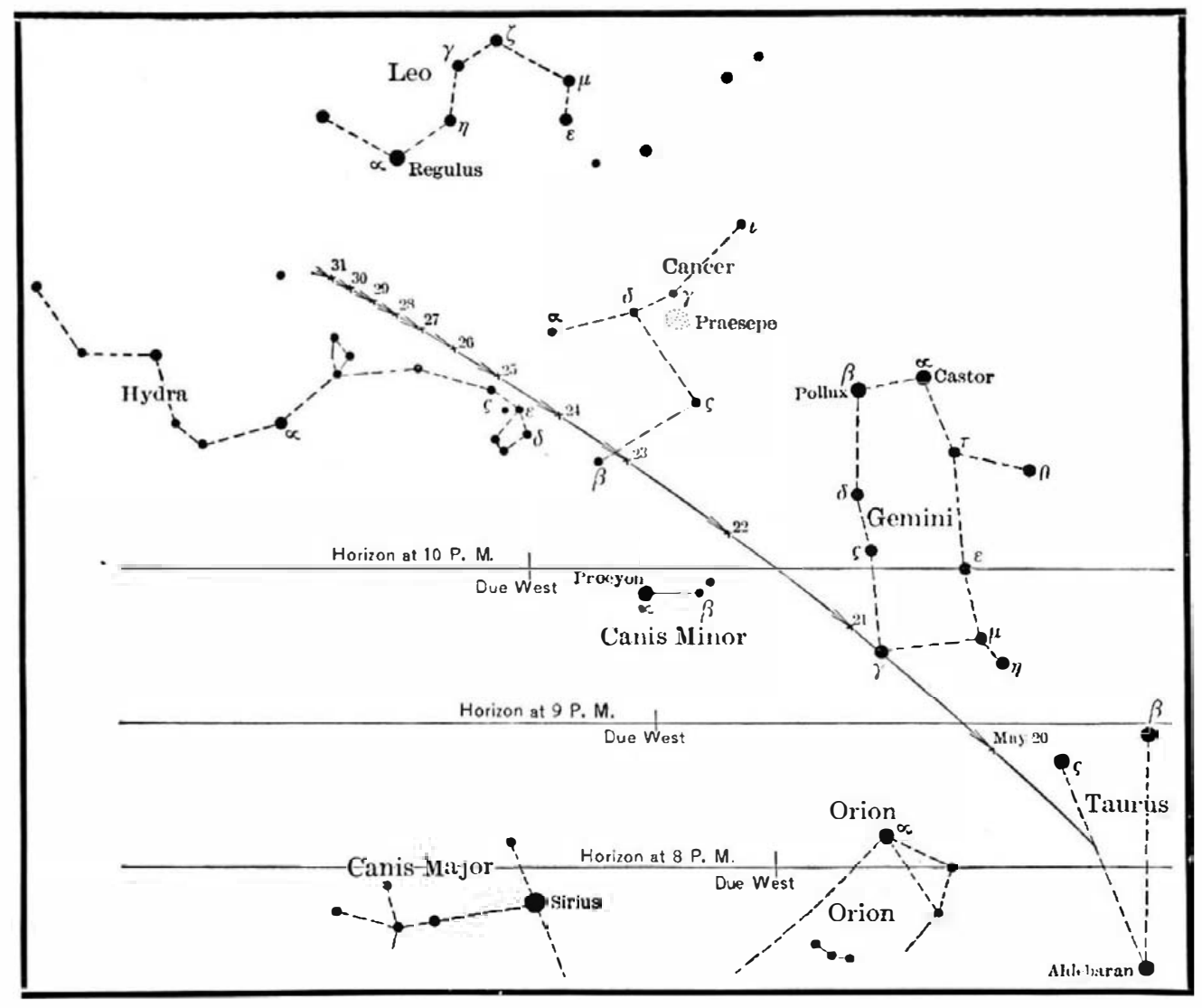

TRACK OF HALLEY'S COMET AND NEIGHBORING STARS, MAY 20-31, 1910.
Isle of Wight alternately moves forward and backward with the variation of the tides, the greater pressure of the water at high tide in the English Channel as compared with that in the Solent and Spithead causing the island to be tilted upward bodily from the channel side.

His latest experiments in this direction have been carried out in connection with the Irish Sea at the mouth of the Mersey. A special type of seismic recorder has been devised and has been set up in an underground position at Bidston Observatory near Liverpool, some two miles from the water's edge. The apparatus comprises, as it were, a mast and a boom, such as is used in the professor's earthquake recorders, the boom being free, so that as the mast moves in one direction or another the boom can also move. A photographic recorder is connected to the apparatus so as to secure a permanent visual record of the oscillations. The instrument is far more sensitive than that employed for ordinary seismic operations, thereby indicating those very slight movements of the earth which the ordinary apparatus would ignore.

The records secured by this instrument conclusively prove that twice every twenty-four hours the opposite sides of the tidal basin are drawn closer together, the phenomena occurring at high tide when the increased volume and weight of water piled up in the Irish Sea and pressing on its bed causes the latter to sag somewhat. The action can be watched, for when the tide is flowing quickly and the tide is high the pendulum moves a considerable distance and keeps pace with the deflection due to the increasing load. At Bidston the weight of the tide off the mouth of the Mersey causes a deflection of about one inch in a distance of sixteen miles. As the tide ebbs and the weight is reduced the sag diminishes like a dent in an India rubber ball, and the banks on either side slowly recede from one another. The extent of this attracting and repelling movement would be more accentuated upon the instrument were the latter placed nearer the sea, and Prof. Milne points out that for this reason observatories should not be situated too near tidewater. The regular alternate movements of the apparatus in opposite directions every six hours not only, as it were, record the extent of the elasticity of the earth's crust, demonstrating that it is responsive to pulls and strain to a far greater degree than is generally believed, but also weigh the tide itself. The result of these experiments should provide a new field for investigating tidal forces and nhenomena, and possibly contribute to our knowledge thereof.

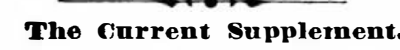

Almost the entire issue of the current Supplement, No. 1793, is devoted to a complete description of what is known as the New York Tunnel Extension of the can be inclined and moved vertically and horizontally by means of the joints of the supports. The rods are used horizontally if the bust is to have the same scale as the photographs, and are inclined for enlargements and reductions. The movement of the photograph frames in the guides is limited by fixed stops, so that the frames can be removed and replaced exactly in their former positions.

The rods and their supports are adjusted to bring the inner end of the $\operatorname{rod} A$ into contact with a conspicuous point, the tip of the nose, for example, in the full face photograph $T$, and the inner end of $B$ into contact with the corresponding point of the profile $E$. The frames containing the photographs are then removed and the rods $A$ and $B$ are pushed inward in their supports until their inner ends meet. The point of meeting determines the position of the top of the nose of the bust. The post at the center of the table is covered with clay or other plastic material, which is built out until this point is established in tangible form. The rods are then drawn back, the photographs replaced and a second point of the face is established by a repetition of the process. In this way numerous points distributed over every part of the bust are fixed, each pair of adjacent sides of the table, and the corresponding pair of photographs, being employed, as required. The result is an almost complete sketch, obtained from a sitting of a few seconds. All of these operations can be performed by a skilled workman. The hand of the sculptor is called into requisition only to give a few finishing touches, in another brief sitting, and to impress an individual artistic character upon the work. (lower down, between these and Regulus). With these as guides, the other stars

and the comet identified.

From present indications it is probable that at first (on the 20th and 21st) the comet will be as bright as these bright stars and visible at a glance. Towar the end of the month it will be much fainter, but probably still easily visible to the naked eye.

The tail will extend upward and to the left, practically along the line of the comet's apparent path How long it will be it is even yet impossible to say. At first the light of the moon (which is full on the night of the 23rd) will drown out the fainter part of the tail, but later, when it is out of the way, these may perhaps be seen, though the comet will be so much farther off that, on the whole, it will hardly be so fine a sight.

In observing it telescopically, the eyepiece of lowest power, giving the largest field of view, will be most satisfactory.

Princeton University Observatory.

\section{The Elasticity of the Earth.}

Some interesting experiments have recently been carried out by Prof. Milne, F.R.S., the well-known authority on seismology, to demonstrate the elasticity of the earth especially under the influence of the tides. Some years ago he showed that valleys during the day are of greater width than at night, there bein an expansion or opening out under the action of the sun and a contraction or closing up in the hours of darkness. He also showed by means of seismographi darkness. He also showed by means of seismographic
records secured at his observatory at Shide, that the
Pennsylvania Railroad, the costliest improvement ever made by a railroad, and one of the most far-reaching importance to industry and to the traveler. Many pictures are published, showing the excavations which were made, the progress of the work, as well as the completed station. Dr. Otto Hoffmann writes interestingly on the system of the universe. Carbon tetrachloride possesses in comparison with carbon disulphide, benzine, gasoline, and other petroleum products used for the extraction of oils and fats, the advantage of freedom from inflammability, which reduces the danger of fire and the cost of insurance. Hence it is used frequently as a harmless substitute for benzine and gasoline in cleaning clothes. An article on the subject appears in the Supplement. Mr. Henry A. Wise Wood's excellent paper on Modern Stereotypy is concluded.

Recently Mr. W. Casmey, of Leeds, read a paper before the Rotherham Engineering Society on "Engineering in the Boiler House." Mr. Casmey stated that there was an indication that the factory chimney would be supplanted by mechanical drafts or fans, as the cost of maintaining steam by such methods was only about one-sixth that of chimney draft. He pointed out that while steam gages and water indicators had long been in use, stokers had no assist. ance in ascertaining the volume of air necessary for combustion. A full combination indicator had, how ever, been invented for this purpose, consisting of a gage actuated by the draft of the chimney and having a graduated scale giving the pounds weight of coal burned to the square foot of grate per hour. 